\title{
Sulfur-Modified Copper Catalysts for the Electrochemical Reduction of Carbon Dioxide to Formate
}

Tatsuya Shinagawa, ${ }^{\dagger}$ Gastón O. Larrazábal, ${ }^{\dagger}$ Antonio J. Martín, ${ }^{\dagger}$ Frank Krumeich, ${ }^{\S}$ and Javier Pérez-Ramírez ${ }^{*}+{ }^{\dagger}$

${ }^{\dagger}$ Institute for Chemical and Bioengineering, Department of Chemistry and Applied Biosciences, ETH Zurich, Vladimir-Prelog-Weg 1, 8093 Zurich, Switzerland

${ }^{\S}$ Laboratory of Inorganic Chemistry, Department of Chemistry and Applied Biosciences, ETH Zurich, Vladimir-Prelog-Weg 1, 8093 Zurich, Switzerland

\section{Supporting Information}

ABSTRACT: The electrocatalytic $\mathrm{CO}_{2}$ reduction reaction $\left(\mathrm{eCO}_{2} \mathrm{RR}\right)$ has been gaining increasing attention owing to its potential to contribute to sustainability in our society, although enhanced catalytic performance is a prerequisite for its implementation. Herein, $\mathrm{Cu}$ electrocatalysts modified with sulfur proved to selectively produce formate via aqueous $\mathrm{eCO}_{2} \mathrm{RR}$ and thus to unexpectedly prevent the mechanistic fingerprint of $\mathrm{Cu}$ (i.e., the $\mathrm{CO}$ path). Initially, sulfur-modified copper catalysts $(\mathrm{Cu}-\mathrm{S})$ were prepared by the in situ reductive reconstruction of nano $\mathrm{CuS}$ precursors, revealing a positive correlation between particle size and selectivity toward formate. Subsequent studies over targeted submicron $\mathrm{Cu}-\mathrm{S}$ particles with varying sulfur content demonstrated their evolution under reaction conditions, attaining a similar surface state comprising metallic $\mathrm{Cu}$ and sulfide phases, irrespective of the initial structure of the materials. In

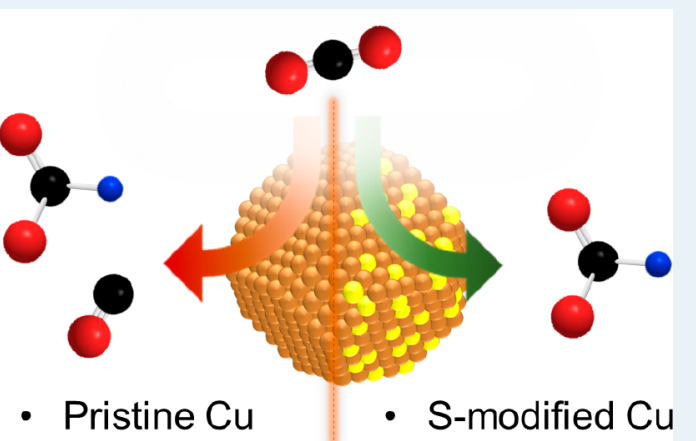
accordance, the initial sulfur content showed only a very limited influence on the catalytic performance, which remained at approximately $80 \%$ Faradaic efficiency toward formate at $-0.8 \mathrm{~V}$ vs RHE, outperforming all cost-effective, earth-abundant, and nontoxic electrocatalysts reported to date for the production of formate via the aqueous $\mathrm{eCO}_{2} \mathrm{RR}$.

KEYWORDS: electrocatalysis, $\mathrm{CO}_{2}$ reduction, formate, copper, sulfide

\section{INTRODUCTION}

The conversion of $\mathrm{H}_{2} \mathrm{O}$ and $\mathrm{CO}_{2}$ into fuels and value-added compounds in combination with renewable energy sources may effectively contribute to establishing a more sustainable circulation of energy and materials. ${ }^{1,2}$ In this context, the electrocatalytic $\mathrm{CO}_{2}$ reduction reaction $\left(\mathrm{eCO}_{2} \mathrm{RR}\right)$ has been attracting increasing attention, owing to its potential contribution to closing the carbon cycle. ${ }^{3-6}$

Since the pioneering works of Hori and co-workers, ${ }^{3,7,8}$ a number of materials have been examined as catalysts for the $\mathrm{eCO}_{2} \mathrm{RR}$ in aqueous media. ${ }^{6}$ Among the $\mathrm{eCO}_{2} \mathrm{RR}$-active metal electrodes, gold and silver are known for their comparatively high activity toward $\mathrm{CO},{ }^{8}$ whereas palladium and some p-block elements, such as tin and indium, direct the reaction toward the production of formate. ${ }^{8}$ Copper electrodes are unique due to the production of highly reduced compounds, such as hydrocarbons and alcohols, in appreciable amounts at high overpotentials. $^{8}$ On the basis of density functional theory (DFT) calculations, Nørskov and co-workers ${ }^{9,10}$ identified a linear correlation between the binding energies of reaction intermediates on transition-metal surfaces, which dictates their electrocatalytic activity toward the $\mathrm{eCO}_{2} \mathrm{RR} .{ }^{10}$ In this framework, the exceptional behavior of $\mathrm{Cu}$ in this reaction was rationalized by the mild adsorption energy of $\mathrm{CO}$, which is a key reaction intermediate. ${ }^{10}$ Nevertheless, pristine $\mathrm{Cu}$ electrodes show impractical overpotentials for the $\mathrm{eCO}_{2} \mathrm{RR}$ and appreciable activity for the competing hydrogen evolution reaction (HER), $8,11,12$ leading to poor selectivity. However, the aforementioned scaling relationship naturally constrains any performance optimization associated with simply tuning the electronic structure of the d-metal electrocatalysts. As a consequence, nonconventional approaches to break the scaling relationship are urgently required.

In this context, Kanan et al. ${ }^{13}$ reported in 2012 that a $\mathrm{Cu}$ electrode derived from its oxide (oxide-derived copper; OD$\mathrm{Cu}$ ) exhibited improved performance toward $\mathrm{CO}$ and $\mathrm{HCOO}^{-}$ at low overpotentials. The origin of such improvements is still under debate; claims on the active role of grain boundaries formed upon the reduction of copper oxide ${ }^{13,14}$ contrast with persistent interstitial oxygen on the subsurface of $\mathrm{OD}-\mathrm{Cu}$ positively modulating the electronic structure. ${ }^{15,16}$ This finding opened up a new research direction targeting $\mathrm{Cu}$-based

Received: September 15, 2017

Revised: November 17, 2017

Published: December 11, 2017 
materials modified with elements other than transition metals. In this respect, a successful modification of $\mathrm{Cu}$ with $\operatorname{In}^{17,18}$ or $\mathrm{Sn}^{19}$ was reported by Takanabe and co-workers, as reflected by Faradaic efficiencies (FEs) for CO greater than 90\% at relatively small overpotentials $(\sim 400 \mathrm{mV})$. Later on, rationalization shed light on the complexity inherent to those systems. ${ }^{20,21}$ p-Block modifiers are thought to participate in the formation of bonds on the surface according to theoretical studies, hence circumventing the scaling relationships. ${ }^{22}$ Overall, these studies point to the potential of p-block elements as modifiers to tune the catalytic properties of $\mathrm{Cu}$ toward different $\mathrm{eCO}_{2} \mathrm{RR}$ products.

From this standpoint, sulfur is an attractive candidate as a modifier due to its chemical similarities with oxygen. Herein, we describe the selective formation of formate over particulate sulfur-modified $\mathrm{Cu}(\mathrm{Cu}-\mathrm{S})$ electrocatalysts prepared from sulfide precursors upon reductive reconstruction. The study of the influence of the particle size and sulfur content on the catalytic response unveiled a size-activity relationship correlating larger particle sizes with higher FEs to formate. Detailed characterization allowed us to gain insights on the catalytic role of sulfur, distribution, and chemical nature. In view of these results and the high practical relevance of formate as additive ${ }^{23,24}$ and potential hydrogen carrier, ${ }^{25-27}$ and its predicted leading role in breaking the barrier for $\mathrm{eCO}_{2} \mathrm{RR}$ implementation, ${ }^{28}$ we developed a targeted preparation route toward practical systems comprising submicron-sized $\mathrm{Cu}-\mathrm{S}$ that indeed exhibited enhanced performance $(>80 \%$ FEs at $-0.8 \mathrm{~V}$ vs reversible hydrogen electrode; RHE), outperforming reported earth-abundant and cost-effective materials for formate production via the aqueous $\mathrm{eCO}_{2} \mathrm{RR}^{6}$

\section{EXPERIMENTAL SECTION}

2.1. Catalyst Preparation. Carbon-supported copper sulfide catalysts were prepared by wet chemistry under $\mathrm{He}$ atmosphere. Urea (200 mmol, Sigma-Aldrich, $\geq 99.5 \%)$ and appropriate amounts of thiourea (Sigma-Aldrich, > 95\%), $\mathrm{Cu}\left(\mathrm{NO}_{3}\right)_{2} \cdot 3 \mathrm{H}_{2} \mathrm{O}$ (Sigma-Aldrich, $\geq 99.0 \%$ ) and carbon black (Vulcan XC-72, Cabot Corporation) were first mixed in 18.2 $\mathrm{M} \Omega \mathrm{cm}$ ultrapure water $\left(200 \mathrm{~cm}^{3}\right)$ at $298 \mathrm{~K}$ for $1 \mathrm{~h}$. Equimolar amounts $(0.05,0.2,0.5$, and $2.0 \mathrm{mmol})$ of thiourea and copper nitrate were employed for preparing four different samples, denoted as CuS-1, $-2,-3$, and -4 , respectively, while the amount of carbon black was varied to target a $\mathrm{CuS}$ loading of 5 wt \% in each catalyst. The mixture was then heated to $363 \mathrm{~K}$ under vigorous stirring, kept at this temperature for $1 \mathrm{~h}$, and then allowed to naturally cool to room temperature. The resulting mixture was washed with ultrapure water three times by centrifugation $(6000 \mathrm{rpm}, 10 \mathrm{~min})$, and the obtained powders were dried under vacuum overnight at $353 \mathrm{~K}$. Further details on the synthesis are provided in the Supporting Information (SI).

Unsupported bulk copper sulfide was prepared by a solvothermal route adopted from $\mathrm{Wu}$ et al. ${ }^{21,29}$ Briefly, 4 mmol of $\mathrm{Cu}\left(\mathrm{NO}_{3}\right) \cdot 3 \mathrm{H}_{2} \mathrm{O}$ and elemental sulfur (Sigma-Aldrich, $>95 \%$ ) were mixed in $40 \mathrm{~cm}^{3}$ of ethylene glycol (SigmaAldrich, 99\%) at room temperature for $>30 \mathrm{~min}$. We carried out syntheses with different amounts of sulfur (0.016, 0.037, $0.066,0.14,0.63$, and $6.5 \mathrm{mmol}$ ) to tune the sulfur content of the resulting materials. The mixture was then transferred into a $50 \mathrm{~cm}^{3}$ Teflon-lined autoclave, and heat treated at $413 \mathrm{~K}$ for 12 h. The obtained mixture was washed and dried as described.
2.2. Electrode Preparation. The prepared electrocatalyst powders were deposited on a carbon gas diffusion layer (GDL) by airbrushing. A catalyst ink was prepared by dispersing the catalyst powder $(50 \mathrm{mg})$ in a 1:1 mixture of ultrapure water $(4$ $\left.\mathrm{cm}^{3}\right)$ and 2-propanol $\left(4 \mathrm{~cm}^{3}\right.$, Sigma-Aldrich, $\left.99.8 \%\right)$ to which Nafion solution ( $50 \mathrm{~mm}^{3}, 5$ wt \%, Sigma-Aldrich) was also added as a binder phase. The resulting mixture was sonicated for $15 \mathrm{~min}$ and then was sprayed onto the GDL (Sigracet 39BC, SGL Group) with an airbrush (Iwata Eclipse HP-SBS) at $353 \mathrm{~K}$. A total powder loading of $1.5 \mathrm{mg} \mathrm{cm}^{-2}$ was typically achieved for each electrode.

2.3. Electrochemical Tests. A custom gastight glass cell with two compartments separated by a Nafion 212 membrane (Alfa Aesar, $0.05 \mathrm{~mm}$ thickness) was used for the electrochemical studies. Both chambers were filled with $40 \mathrm{~cm}^{3}$ of a $0.1 \mathrm{M} \mathrm{KHCO}_{3}$ solution (Sigma-Aldrich, 99.95\% trace metals basis) prepared with ultrapure water. Before and during the measurement, $\mathrm{CO}_{2}$ (Messer, purity 4.8) was supplied to the catholyte at a flow rate of $20 \mathrm{~cm}^{3} \mathrm{~min}^{-1}$, resulting in a $\mathrm{pH}$ of 6.7. A Pt wire and a $\mathrm{Ag} / \mathrm{AgCl}(3.0 \mathrm{M} \mathrm{KCl})$ were used as the counter and reference electrode, respectively. The working electrodes had a geometric area of ca. $1 \mathrm{~cm}^{2}$, which was accurately quantified for each electrode with the ImageJ image processing and analysis software (Wayne Rasband, National Institutes of Health). All measurements were performed employing an Autolab PGSTAT302N potentiostat at room temperature. Current densities were normalized by the geometric surface area; and potentials were $i R$ corrected (impedance spectroscopy, $100 \mathrm{kHz}, 10 \mathrm{mV}$ amplitude), and referenced to the reversible hydrogen electrode (RHE).

The double layer capacitance was measured by cyclic voltammograms $(\mathrm{CV})$ in the potential range of open circuit potential $\pm 15 \mathrm{mV}$ at varying scan rates $(2,5,10,15$, and 20 $\left.\mathrm{mV} \mathrm{s}{ }^{-1}\right)$. The $\mathrm{eCO}_{2} \mathrm{RR}$ performance was investigated by chronoamperometry (CA) for $1.5 \mathrm{~h}$. Typically, the measurements were repeated several times. Averaged values are reported in this study. Gaseous products were analyzed using an online gas chromatograph (GC; SRI 8610C, Multi-Gas \#3 configuration) with $\mathrm{Ar}$ as a carrier gas at a head pressure of 2.3 bar. Gas samples were injected and analyzed $10 \mathrm{~min}$ after the start of the electrolysis and thereafter every $15 \mathrm{~min}$. The GC was equipped with a HayeSep D column and a Molecular Sieve $13 \mathrm{X}$ column. Liquid products were examined with a highperformance liquid chromatograph in a Merck LaChrom system equipped with a Bio-Rad Aminex HPX-87H column heated at $333 \mathrm{~K}$ and a refractive index detector (Hitachi Chromaster 5450), using $5 \mathrm{mM} \mathrm{H}_{2} \mathrm{SO}_{4}$ as eluent.

2.4. Catalyst Characterization. X-ray diffraction (XRD) patterns were obtained using a PANalytical X'Pert PRO-MPD diffractometer with Bragg-Brentano geometry using Nifiltered $\mathrm{Cu} \mathrm{K} \alpha$ radiation $(\lambda=0.1541 \mathrm{~nm})$. The instrument was operated at $40 \mathrm{~mA}$ and $45 \mathrm{kV}$, and the patterns were recorded in the $10-70^{\circ} 2 \theta$ range with an angular step size of $0.05^{\circ}$ and a counting time of $180 \mathrm{~s}$ per step. The content of elements in the samples was quantified by X-ray fluorescence (XRF) spectroscopy using an Orbis Micro-XRF analyzer equipped with a $35 \mathrm{kV} \mathrm{Rh}$ anode and a silicon detector. The loading of copper in the supported catalyst was analyzed by inductively coupled plasma optical emission spectrometry (ICP-OES) using a Horiba Ultima 2 instrument. X-ray photoelectron spectroscopy (XPS) analysis was carried out with a PHI Quantum 2000 spectrometer (Physical Electronics) equipped with a $180^{\circ}$ spherical capacitor energy analyzer, at a 
base pressure of $5 \times 10^{-7} \mathrm{~Pa}$ using monochromatic $\mathrm{Al} \mathrm{K} \alpha$ radiation $(1486.68 \mathrm{eV})$. The binding energy scale was calibrated with the $\mathrm{C} 1 \mathrm{~s}$ signal at $284.8 \mathrm{eV}$. Scanning electron microscopy (SEM) and backscattered electron (BSE) micrographs and energy dispersive X-ray (EDX) spectroscopy maps were acquired in a FEI Quanta 200F instrument. Powdered samples were dispersed in dry form onto fresh carbon paint deposited on an aluminum holder. In addition, scanning transmission electron microscopy (STEM) investigations combined with EDX mappings were performed in a FEI Talos F200X (high-brightness gun (XFEG)) at an accelerating voltage of $200 \mathrm{kV}$. STEM images $(1024 \times 1024$ pixels $)$ were recorded with a high-angle annular dark field (HAADF) detector at a frame rate of ca. $15 \mathrm{~s}$. The selected imaging conditions give rise to atomic number $(Z)$ contrast. Four silicon drift detectors attached to the Talos F200X microscope allowed for recording EDX maps with high signal/noise (S/N) ratio (measuring time: ca. $10 \mathrm{~min}$ ) using the program Esprit 1.9 (Bruker).

\section{RESULTS AND DISCUSSION}

3.1. Nanosized CuS/C. Based on the potential similarities between the oxygen and sulfur modification of $\mathrm{Cu}$-based $\mathrm{eCO}_{2} \mathrm{RR}$ catalysts, we adopted a safe and potentially scalable approach (i.e., avoiding high-temperature treatments with $\mathrm{H}_{2} \mathrm{~S}$ ) for the preparation of sulfur-modified $\mathrm{Cu}$ electrocatalysts in a practical form. To this end, size-controlled copper sulfide catalysts loaded on a carbon support (Vulcan XC-72) were prepared by a wet chemistry route. The XRD analysis (Figure 1a) of the catalysts showed diffraction peaks compatible with
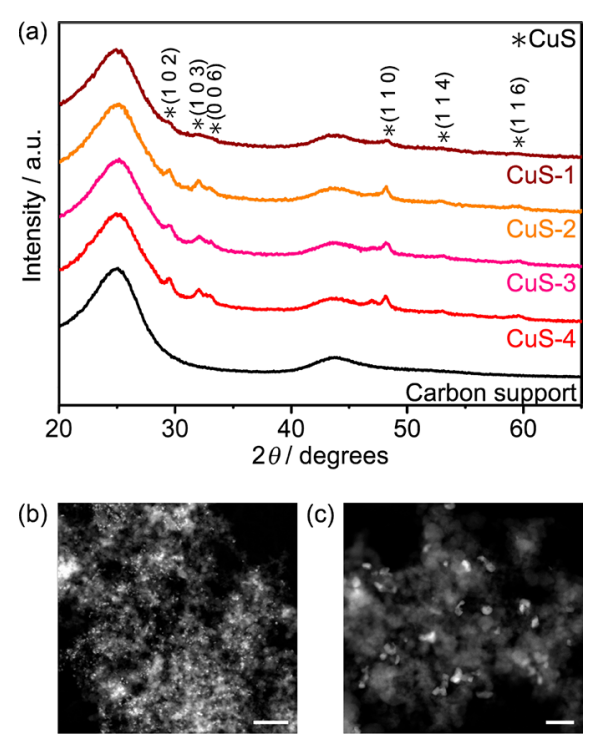

Figure 1. (a) X-ray diffraction (XRD) patterns of CuS-1 to CuS-4. Representative scanning transmission electron microscopy (STEM) images of CuS-3 in (b) wide and (c) magnified views. The XRD pattern of the carbon support is added as a reference. Scale bar: (b) $500 \mathrm{~nm},(\mathrm{c}) 100 \mathrm{~nm}$.

stoichiometric $\mathrm{CuS}$ (except for one peak at $47^{\circ} 2 \theta$ ascribable to $\mathrm{Cu}_{1.8} \mathrm{~S}$ ), while such clear peaks were less defined for $\mathrm{CuS}-1$ presumably due to its smaller size (vide infra), confirming the successful preparation of CuS. Additionally, STEM observations disclosed their nanometric nature. Figure $1 \mathrm{~b}, \mathrm{c}$ show representative STEM images (material shown: CuS-3, see SI Figure S1 for the other materials) exhibiting dispersed nanometer-sized particles on carbon black. An effective control of the particle size was achieved by varying the concentration of the copper and sulfur precursors in the synthesis protocol (SI Figure S2), as evidenced by a recognizable increase of the mean particle size in different samples (Table 1). The surface

Table 1. Minimum, Maximum, and Average Particle Sizes of Nanosized $\mathrm{Cu}-\mathrm{S}$ Obtained from STEM Images

\begin{tabular}{|c|c|c|c|c|c|c|}
\hline \multirow[b]{2}{*}{ sample } & \multicolumn{2}{|c|}{ size $/ \mathrm{nm}$} & \multicolumn{2}{|c|}{ av size/nm } & \multirow[b]{2}{*}{$\sigma /-$} & \multirow[b]{2}{*}{$\mathrm{Cu}$ loading ${ }^{a} /$ wt $\%$} \\
\hline & $\min$ & $\max$ & mean & $50 \%$ & & \\
\hline $\mathrm{CuS}-1$ & 4 & 41 & 15 & 15 & 7 & 3.6 \\
\hline $\mathrm{CuS}-2$ & 12 & 75 & 34 & 31 & 12 & 3.8 \\
\hline $\mathrm{CuS}-3$ & 11 & 63 & 33 & 33 & 10 & 3.1 \\
\hline $\mathrm{CuS}-4$ & 15 & 78 & 42 & 39 & 14 & 2.2 \\
\hline
\end{tabular}

${ }^{a}$ Determined by inductively coupled plasma optical emission spectrometry.

state of the CuS/C catalysts was evaluated by XPS analysis of the corresponding electrodes. Spectra for $\mathrm{CuS}-1$ and $\mathrm{CuS}-4$ are presented in Figure 2 and in SI Figure S3. In the S 2 p region (Figure 2a), the broad peak observed at $162.5 \mathrm{eV}$ in both $\mathrm{CuS}-1$ and $\mathrm{CuS}-4$ is ascribable to any of the copper sulfide phases (i.e., $\mathrm{Cu}_{2} \mathrm{~S}$ or $\mathrm{CuS}$ ). ${ }^{30} \mathrm{In}$ addition, the signal at higher binding energies can be assigned to sulfur species in Nafion (used as binder in the catalyst ink) as well as to sulfate species presumably formed by the oxidation of sulfides upon exposure to air. ${ }^{31}$ In the $\mathrm{Cu} 2 \mathrm{p}$ region (Figure $2 \mathrm{~b}$ ), both samples exhibited a sharp peak centered at ca. $932 \mathrm{eV}$, which likely originated from contributions from two distinct $\mathrm{Cu}$ species: one from $\mathrm{Cu}^{+}$in $\mathrm{Cu}_{2} \mathrm{O}(932.5 \mathrm{eV})$ accounting for more than half of the total area (ca. 55\%, see spectral fitting in SI Figure S3), and the other at a lower binding energy (ca. $932 \mathrm{eV}$ ) ascribable to copper sulfides, ${ }^{30}$ consistent with the $S 2 p$ spectra. There was no apparent contribution originating from $\mathrm{CuO}$. To better elucidate the $\mathrm{Cu}$ state in the samples, the Auger emission (AE) spectra in the $\mathrm{Cu}$ LMM region were also analyzed (Figure $2 \mathrm{c}$ ). Both $\mathrm{CuS}-1$ and $\mathrm{CuS}-4$ exhibited a signal centered at $917.5 \mathrm{eV}$, which indicates the presence of both $\mathrm{Cu}^{+}$ (in $\mathrm{Cu}_{2} \mathrm{O}$ and/or $\mathrm{Cu}_{2} \mathrm{~S}$ at $917 \mathrm{eV}$ ) and $\mathrm{Cu}^{2+}$ (in $\mathrm{CuS}$ at 918 $\mathrm{eV})$ with a relatively similar composition. ${ }^{30}$ Taken together, these observations suggest the formation of nanometrically shaped copper sulfide phase $\mathrm{CuS}$, although the presence of metallic/oxidic $\mathrm{Cu}$ decorating the surface is plausible.

The catalytic performance of the $\mathrm{CuS} / \mathrm{C}$ for the $\mathrm{eCO}_{2} \mathrm{RR}$ was assessed by $1.5 \mathrm{~h}$ electrolyses in $\mathrm{CO}_{2}$-saturated $0.1 \mathrm{M}$ $\mathrm{KHCO}_{3}(\mathrm{pH} 6.7)$ at -0.6 and $-0.8 \mathrm{~V}$ vs $\mathrm{RHE}$ (Figure 3). Carbon black (Vulcan XC-72) was chosen as the conductive support due to its almost inert catalytic nature (SI Figure S4). Remarkably, formate was observed as the main $\mathrm{eCO}_{2} \mathrm{RR}$ product over all $\mathrm{CuS} / \mathrm{C}$ catalysts, with only trace amounts of $\mathrm{CO}$ detected at $-0.8 \mathrm{~V}$ vs RHE. Moreover, the FE to formate $\left(\mathrm{FE}_{\mathrm{HCOO}}{ }^{-}\right)$as well as the current density increased almost monotonically from $\mathrm{CuS}-1$ to $\mathrm{CuS}-4$ at both potentials, accompanying the increase of the particle size.

Notably, CuS is not thermodynamically stable under the $\mathrm{eCO}_{2} \mathrm{RR}$ conditions. Pourbaix diagrams ${ }^{32}$ (SI Figure S5) clearly dictate an equilibrium potential for the $\mathrm{CuS} / \mathrm{Cu}$ redox pair more positive than the applied working potentials (ca. $-0.3 \mathrm{~V}$ compared to $<-0.6 \mathrm{~V}$ vs $\mathrm{RHE}$ ). Indeed, redox peaks ascribable to $\mathrm{CuS} / \mathrm{Cu}$ were visible in the $\mathrm{CVs}$ prior to the reaction (SI Figure S6), confirming the reduction of $\mathrm{CuS}$ during the $\mathrm{eCO}_{2} \mathrm{RR}$. The reductive loss of $\mathrm{CuS}$ was also 

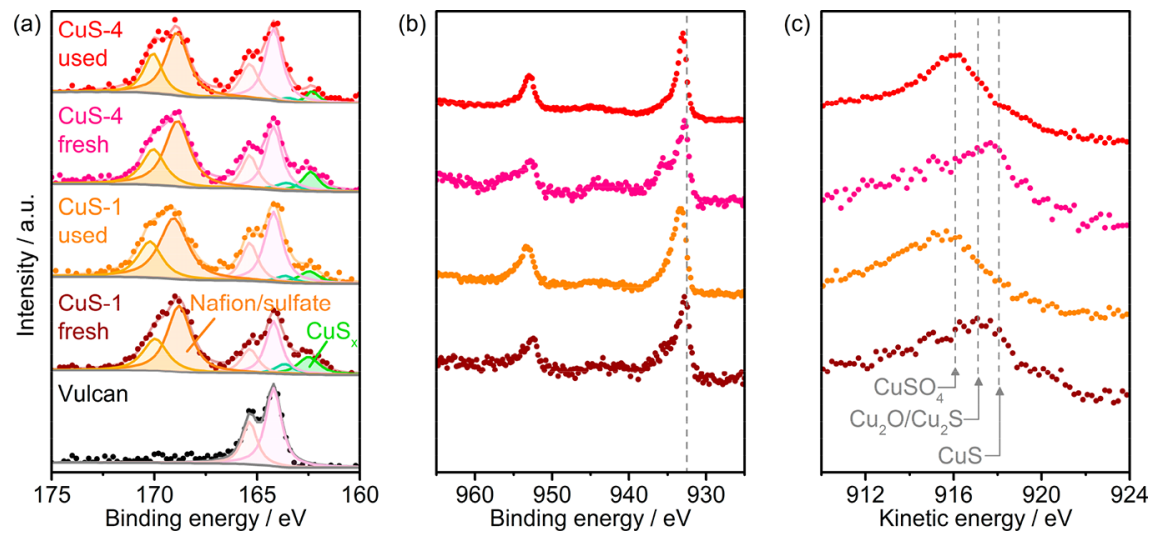

Figure 2. X-ray photoelectron spectroscopy (XPS) analysis and associated deconvolution in the (a) S 2p and (b) Cu 2p regions, and Auger emission (AE) spectra in the (c) Cu LMM region of CuS-1 and CuS-4 before and after the $\mathrm{eCO}_{2} \mathrm{RR}$ test. The XPS spectrum of the carbon support (Vulcan XC-72) is included as a reference. The dashed vertical line in (b) is provided as a visual aid.

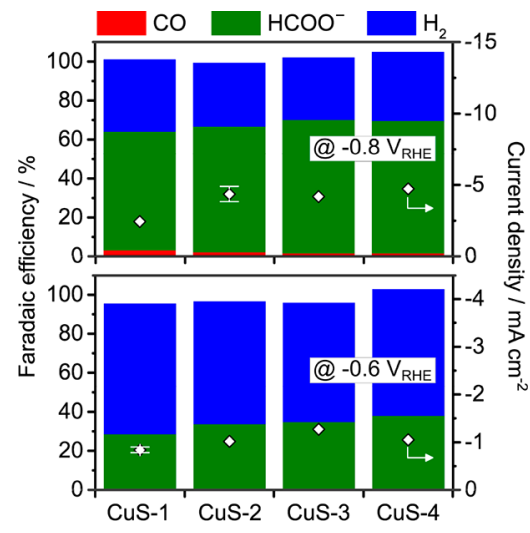

Figure 3. Faradaic efficiency (FE) and total current density over nanosized $\mathrm{Cu}-\mathrm{S}$ catalysts. The data were obtained by chronoamperometry (CA) for $1.5 \mathrm{~h}$, in $0.1 \mathrm{M} \mathrm{KHCO}_{3}$ saturated with $\mathrm{CO}_{2}(\mathrm{pH}$ $6.7)$ at room temperature.

evidenced by XPS analysis. The spectra in the $S 2 p$ region (Figure $2 \mathrm{a}$ ) revealed a considerable decrease of the relative area of the $\mathrm{CuS}$ peak $(162.5 \mathrm{eV})$, which implies that most $\mathrm{CuS}$ phases present in the fresh sample were lost during $\mathrm{eCO}_{2} \mathrm{RR}$. Nevertheless, spectroscopic fingerprints compatible with sulfide phases remain detectable after the reaction, in marked contrast to $\mathrm{OD}-\mathrm{Cu}$, in which the $\mathrm{Cu}_{2} \mathrm{O}$ phase is undetectable upon $\mathrm{eCO}_{2} \mathrm{RR}^{13}$ In tandem, the $\mathrm{Cu} 2 \mathrm{p}$ region did not exhibit considerable changes (Figure $2 \mathrm{~b}$ ), presumably due to the almost identical binding energy for $\mathrm{Cu}_{2} \mathrm{O}$ and copper sulfide. The presence of $\mathrm{Cu}_{2} \mathrm{O}$ could be accounted for by the exposure of the samples to air. ${ }^{21}$ Furthermore, the redox process was accompanied by a drastic structural reconstruction. Figure 4 presents the particle size distributions of the fresh and used samples. CuS-1 (initial size of $15 \pm 7 \mathrm{~nm}$ ) evolved toward an average particle size of ca. $3 \mathrm{~nm}$ after the electrochemical test. Similarly, the particle size of CuS-4 (ca. $42 \mathrm{~nm}$ ) decreased to ca. $5 \mathrm{~nm}$; nevertheless, relatively large particles (i.e., $>20 \mathrm{~nm}$ ) persisted. Overall, these observations illuminated the drastic and presumably fast reductive reconstruction underwent by $\mathrm{CuS}-\mathrm{X}$ materials upon exposure to the $\mathrm{eCO}_{2} \mathrm{RR}$ operation conditions. The detected presence of a potentially persistent sulfide phase on the surface after prolonged operation and the plausible size-performance correlation observed uniquely shape this system and call for further fundamental studies and optimization strategies.

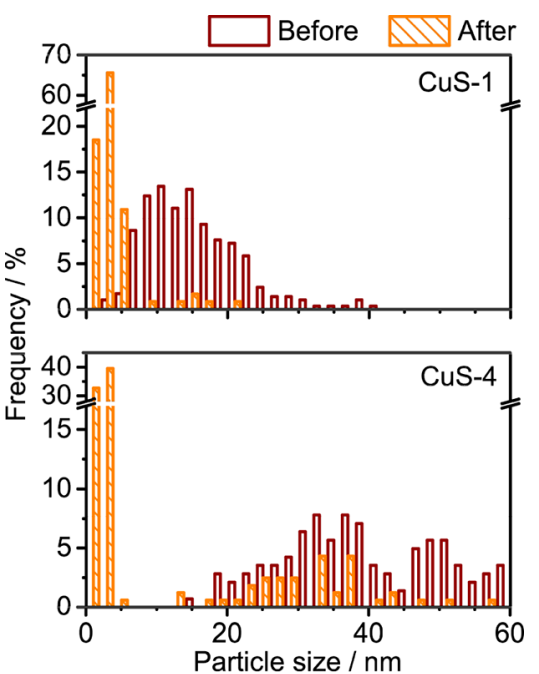

Figure 4. Particle size distribution obtained from STEM images for representative nanosized SD-Cu before and after the $\mathrm{eCO}_{2} \mathrm{RR}$ test.

3.2. Solvothermally Prepared $\mathbf{C u}-\mathbf{S}$ Catalysts. Since the evaluation of the supported catalysts implied a positive correlation between the activity and selectivity for formate and the particle size, bulk S-modified materials were prepared with the aim of verifying this hypothesis and further improving the electrocatalytic performance toward formate while maintaining a powder form that can be readily applied to a practical electrode. ${ }^{21,29}$ The sulfur content of the catalysts, expressed as the relative atomic ratio of sulfur $S /(S+C u)$, was tuned by varying the amount of the sulfur precursor in the solvothermal synthesis (Table 2). The size, morphology, and surface structure of the prepared samples were first studied by microscopy (Figure 5; also SI Figure S7) for representative samples with sulfur contents of 0.45 at\% and 58.9 at\%, denoted as $\mathrm{L}-\mathrm{S}$ and $\mathrm{H}-\mathrm{S}$, respectively. SEM images disclosed a submicron-scale geometry, revealing that bulk materials were successfully obtained, whereas the corresponding EDX elemental maps exhibited 0.6 at $\%$ of sulfur in the L-S sample and 68.5 at $\%$ of homogeneously distributed sulfur in the $\mathrm{H}-\mathrm{S}$ sample. SAED allowed phase identification by exposing diffraction rings indicative of polycrystalline $\mathrm{Cu}_{2} \mathrm{O}$ in $\mathrm{L}-\mathrm{S}$ and of $\mathrm{CuS}$ in $\mathrm{H}-\mathrm{S}$. Further insights on the bulk crystalline structure of the samples were elucidated by XRD analysis. The diffraction patterns shown in Figure 6a revealed that, below a 
Table 2. Quantity of Solid S Used during the Solvothermal Synthesis, the Corresponding Expected S Content, and the Actual S Content in the Resultant Samples Quantified by $\mathrm{X}$ ray Fluorescence (XRF) Spectroscopy

\begin{tabular}{ccc} 
quantity of solid S/mmol & expected S content/at\% & actual S content/at\% \\
0.016 & 0.4 & 0.007 \\
0.037 & 0.9 & 0.009 \\
0.067 & 1.6 & 0.45 \\
0.14 & 3.3 & 1.8 \\
0.63 & 13.7 & 13.1 \\
6.5 & 61.8 & 58.9 \\
\hline
\end{tabular}
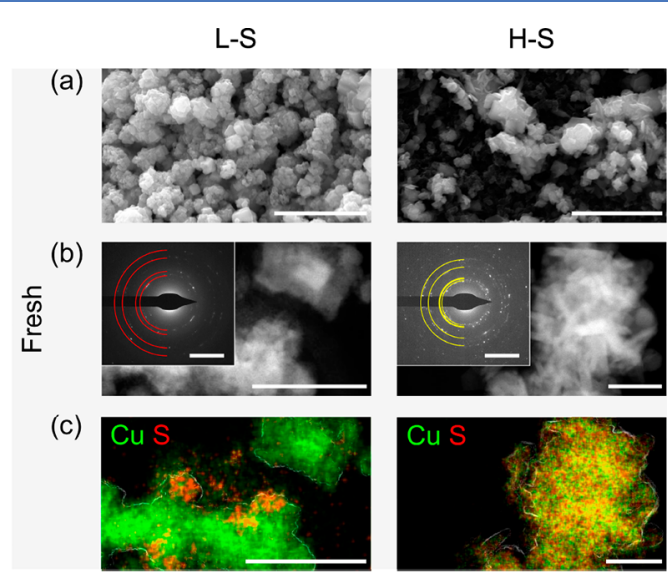

(d)
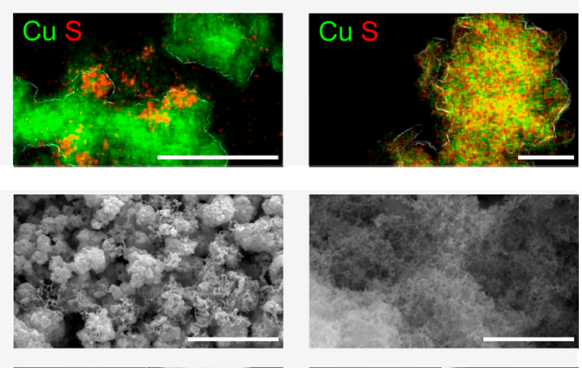

$\stackrel{\text { D্̊n }}{\stackrel{\mathscr{N}}{\supset}(\mathrm{e})}$
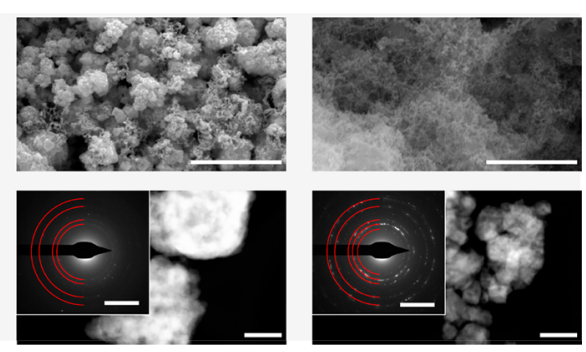

Figure 5. Micrographs of the solvothermally prepared samples: (a), (b), and (c) before, and (d) and (e) after the $\mathrm{eCO}_{2} \mathrm{RR}$ test. (a) Scanning electron microscopy (SEM) images, (b) STEM images in high-angle annular dark field (HAADF) mode and selected area electron diffraction (SAED) in inset, (c) elemental maps obtained by energy-dispersive $\mathrm{X}$-ray spectroscopy (EDX) corresponding to the STEM-HAADF images shown in (b), (d) SEM images, and (e) STEM-HAADF images and SAED patterns (inset). The yellow and red semicircles are overlaid over the diffraction rings corresponding to $\mathrm{CuS}$ and $\mathrm{Cu}_{2} \mathrm{O}$, respectively. White contours delimiting the edges of particles are superimposed as a visual aid in (c). Scale bar: (a) and (d) $2 \mu \mathrm{m}$; (b), (c), and (e) $200 \mathrm{~nm}$; inset in (b) and (e) $51 / \mathrm{nm}$.

sulfur content of 1.8 at $\%, \mathrm{Cu}_{2} \mathrm{O}$ was the main phase together with metallic $\mathrm{Cu}$ in the bulk structure. Associated with the increase of the sulfur content (13.3 at\%), diffraction peaks from $\mathrm{CuS}$ were apparent in addition to the $\mathrm{Cu}_{2} \mathrm{O}$ and $\mathrm{Cu}$ phases, and finally only peaks from $\mathrm{CuS}$ were observed at the highest sulfur content, thus coinciding with the surface crystal structure.

The surface chemical state of the materials was examined by XPS analysis (Figure 6, see SI for the details of the assignment of the spectra). In the $S 2 \mathrm{p}$ region (Figure $6 \mathrm{~b}$ ), the spectroscopic evidence of sulfides was apparent in the $\mathrm{H}-\mathrm{S}$ as reflected by the broad peak at ca. $162 \mathrm{eV}$, which could only be deconvoluted assuming contributions from both $\mathrm{CuS}$ and $\mathrm{Cu}_{2} \mathrm{~S},{ }^{31}$ while the spectrum recorded from $\mathrm{L}-\mathrm{S}$ essentially matched that of a sulfur-free sample. The XPS spectrum in the $\mathrm{Cu} 2 \mathrm{p}$ region and the $\mathrm{Cu}$ LMM Auger emission spectrum (Figure 6c and 6d, respectively; also see SI Figure S8) confirmed $\mathrm{CuS}$ as the major phase in the $\mathrm{H}-\mathrm{S}$ sample, while the spectra from $\mathrm{L}-\mathrm{S}$ and the sulfur-free samples were consistent with $\mathrm{Cu}_{2} \mathrm{O}$ surfaces. Taken together, these results unequivocally associated low concentrations of the precursor with a S-modified copper oxide, whereas above a certain concentration threshold the formation of sulfide phases in the bulk was favored.

Figure 7 summarizes the $\mathrm{eCO}_{2} \mathrm{RR}$ performance of the solvothermally prepared $\mathrm{S}$-modified catalysts in $\mathrm{CO}_{2}$ reduction electrolyses $(1.5 \mathrm{~h}$ ) at $-0.6 \mathrm{~V}$ vs RHE (see also SI Figure S9 for the raw chronoamperometric profile). Trace amounts of incorporated sulfur (i.e., 0.007 at $\%$ ) did not suppress the preference for the HER observed over the unmodified catalyst (i.e., $\mathrm{FE}_{\mathrm{H}_{2}}$ of ca. $70 \%$ ) although a suppression of $\mathrm{CO}$ and a favoring of formate as the main $\mathrm{eCO}_{2} \mathrm{RR}$ product were already evidenced. In contrast, larger sulfur contents triggered a high selectivity toward formate (i.e., $\mathrm{FE}_{\mathrm{HCOO}^{-}}$higher than ca. $45 \%$ ) and a current density of approximately $2.5 \mathrm{~mA} \mathrm{~cm}{ }^{-2}$ which were practically independent of the sulfur content. It is interesting to note that the $\mathrm{eCO}_{2} \mathrm{RR}$ performance observed over the (submicron-sized) solvothermally prepared $\mathrm{Cu}-\mathrm{S}$ catalysts at $-0.6 \mathrm{~V}$ was superior to that of the supported nanosized samples (i.e., $\mathrm{FE}_{\mathrm{HCOO}^{-}}$of ca. $50 \%$ vs less than $40 \%$ ), which supports our hypothesis regarding the existence of a particle size effect in this class of $\mathrm{Cu}-\mathrm{S}$ electrocatalysts.

After the electrochemical test, a surface roughening of the particles was apparent (Figure 5), consistent with the reconstruction observed on the nanosized $\mathrm{Cu}-\mathrm{S}$. Remarkably, both the $\mathrm{L}-\mathrm{S}$ and $\mathrm{H}-\mathrm{S}$ samples exhibited similar contents of sulfur following the electrolysis within the precision available to SEM-EDX quantification (i.e., 0.6 at $\%$ and 1.4 at\%, respectively) in spite of the very large initial difference. This change was also evidenced by the disappearance of the characteristic features of the $\mathrm{CuS} / \mathrm{Cu}$ redox couple in the CVs of the used samples (SI Figure S10). The SAED patterns in Figure $5 \mathrm{e}$ showed that the surface structure of both used samples comprised polycrystalline $\mathrm{Cu}_{2} \mathrm{O}$, which was presumably generated via the oxidation of metallic $\mathrm{Cu}$ that was formed under the cathodic conditions of $\mathrm{eCO}_{2} \mathrm{RR}$ upon the exposure to air. ${ }^{21}$ Interestingly, the presence of sulfides in both $\mathrm{H}-\mathrm{S}$ and L-S samples after the electrolysis become highly plausible after XPS analysis (Figure 6b), although the high noise-tosignal ratio prevented reliable deconvolution in the latter case. Compared with the fresh material, the corresponding peak in $\mathrm{H}-\mathrm{S}$ was shifted toward lower binding energies after the reaction, likely indicating the transformation of $\mathrm{CuS}$ into $\mathrm{Cu}_{2} \mathrm{~S} .{ }^{30}$ The corresponding analyses around $\mathrm{Cu}$ excitations (Figure 6c,d; also see SI Figure S8) showed $\mathrm{Cu}^{+}$as the predominant phase in both cases. Since the oxide phase was most likely formed upon the exposure of the sample to air, ${ }^{21}$ these observations indicate that the cathodic environment of $\mathrm{eCO}_{2} \mathrm{RR}$ induces the loss of excess sulfur in the catalysts and that the S-modified materials, irrespective of the initial sulfur content, attain a similar surface state under the $\mathrm{eCO}_{2} \mathrm{RR}$ conditions, plausibly comprising $\mathrm{Cu}_{2} \mathrm{~S}$ and $\mathrm{Cu}$ as coexisting phases. Such a mechanism would explain the negligible impact of the initial sulfur content in the measured $\mathrm{eCO}_{2} \mathrm{RR}$ performance of the catalysts. However, the observed preference for HER when only trace amounts of the modifier 

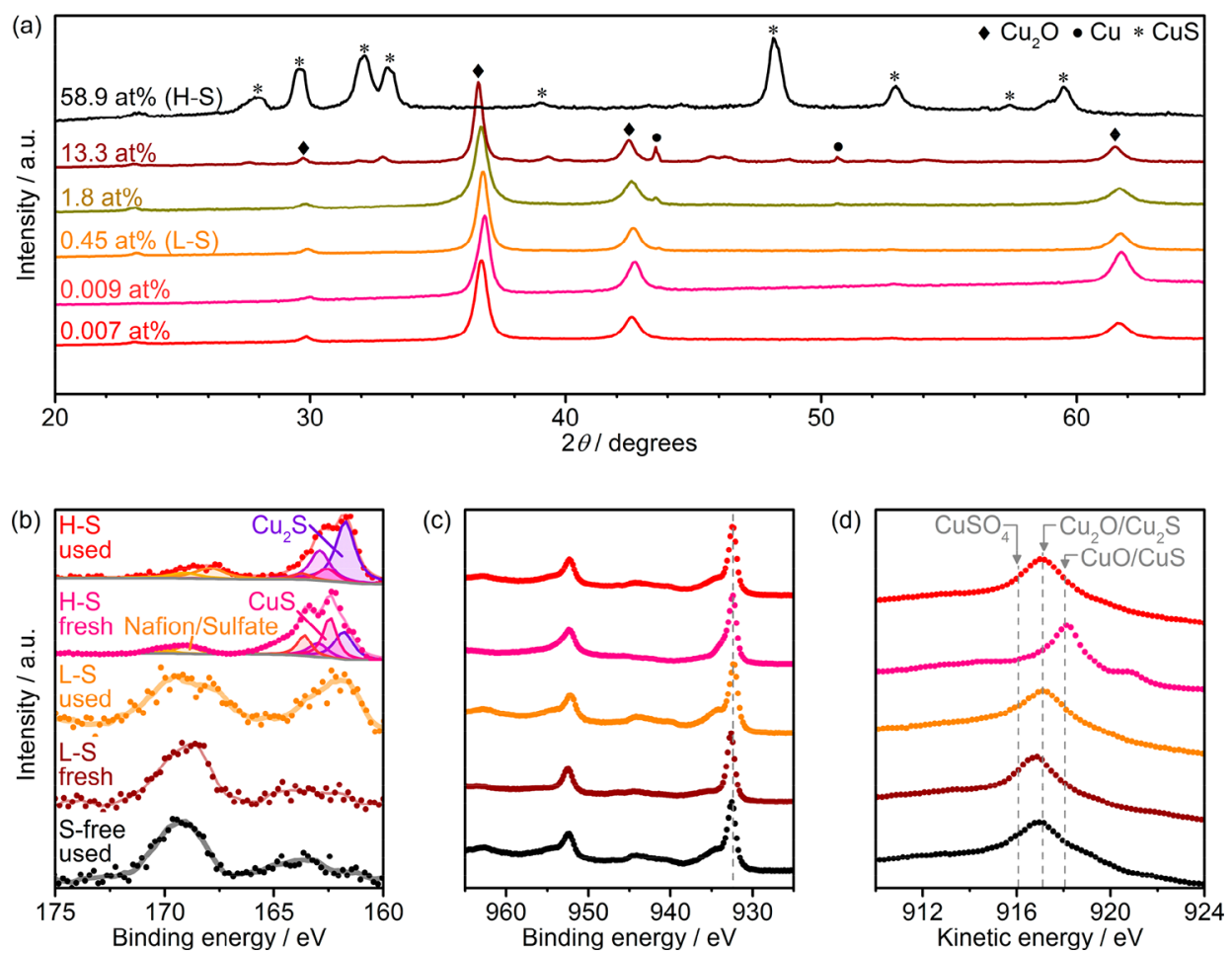

Figure 6. (a) XRD patterns of the solvothermally prepared samples. The sulfur content of the catalysts (defined as the relative atomic ratio of sulfur) as obtained by XRF is indicated. XPS spectra and associated deconvolution in the (b) S 2p and (c) Cu 2p regions, and AE spectra in the (d) $\mathrm{Cu} \mathrm{LMM}$ region of $\mathrm{H}-\mathrm{S}, \mathrm{L}-\mathrm{S}$, and S-free samples before and after the $\mathrm{eCO}_{2} \mathrm{RR}$ test. The dashed vertical lines in (b) and (c) are provided as a visual aid.

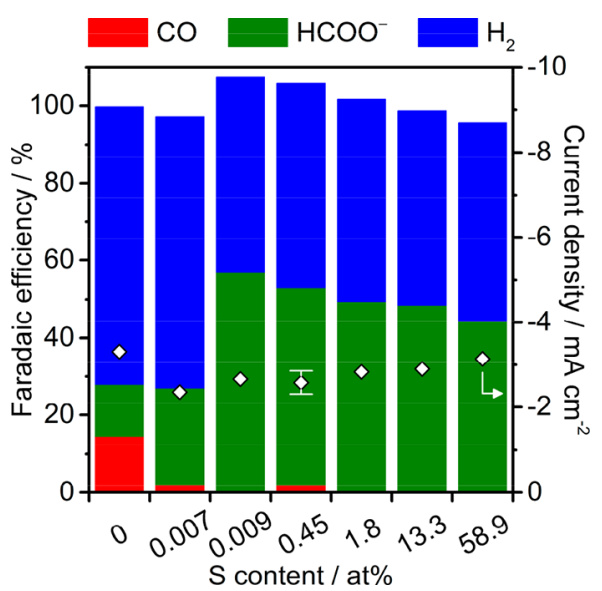

Figure 7. FE and total current density obtained over the solvothermally prepared samples. The data were obtained by $\mathrm{CA}$ at -0.6 vs RHE for $1.5 \mathrm{~h}$, performed in $0.1 \mathrm{M} \mathrm{KHCO}_{3}$ saturated with $\mathrm{CO}_{2}(\mathrm{pH}$ 6.7) at room temperature. The sulfur content determined by $\mathrm{XRF}$ spectroscopy is indicated in the figure.

are present suggests that there is a minimum required amount of sulfur to develop this catalytically advantageous surface configuration.

The $\mathrm{Cu}-\mathrm{S}$ catalysts exclusively produce formate as has been described, which is in marked contrast with pristine $\mathrm{Cu}$, which yields various products including formate, $\mathrm{CO}$, hydrocarbons, and alcohols via $\mathrm{eCO}_{2} \mathrm{RR}^{4,6,8,11} \mathrm{~A}$ plausible reaction mechanism over the pristine $\mathrm{Cu}$ surface was previously proposed on the basis of DFT calculations by Nørskov and co-workers: ${ }^{9,10} \mathrm{CO}_{2}$ is first reduced into either $* \mathrm{COOH}$ or *OCHO intermediate species via one electron and proton transfer. Further reduction of $* \mathrm{COOH}$ generates $* \mathrm{CO}$, which can either desorb as $\mathrm{CO}$ or experience successive reduction events leading to hydrocarbons and/or alcohols (CO path). On the other hand, *OCHO can be converted only into $\mathrm{HCOO}^{-}$upon further reduction $\left(\mathrm{HCOO}^{-}\right.$path), which occurs in parallel to the $\mathrm{CO}$ path. Such a picture is well in line with the experimental studies, ${ }^{4,33-35}$ and a recent report suggested its possible applicability to other metal surfaces. ${ }^{12,36}$ Taking into consideration this reaction mechanism, the exclusive production of formate observed over the herein disclosed $\mathrm{Cu}-\mathrm{S}$ electrocatalysts indicates that the modification of $\mathrm{Cu}$ with sulfur alters the energy levels of the corresponding key intermediate species (i.e., ${ }^{*} \mathrm{COOH}$ and $* \mathrm{OCHO}$ ) and/or $\mathrm{CO}$, leading to partial or complete deactivation of the $\mathrm{CO}$ path. Such a picture might be rationalized in a scenario where the binding energy of *OCHO over the $\mathrm{Cu}-\mathrm{S}$ may be strengthened relative to the pristine $\mathrm{Cu}$ by the presence of positively charged $\mathrm{Cu}$ species, which would be stabilized by adjacent negatively charged sulfur, and thus binding $\mathrm{CO}_{2}$ favorably through the relatively electronegative oxygen. In parallel, this surface configuration is expected to disfavor adsorption of $\mathrm{CO}_{2}$ through the mildly electropositive carbon atom-as in the case of the ${ }^{*} \mathrm{COOH}$ intermediate-hence accounting for the absence of products associated with the $\mathrm{CO}$ path. Nonetheless, we anticipate that further elucidation of the intriguing reaction mechanism over the $\mathrm{Cu}-\mathrm{S}$ electrocatalysts will require a combination of computational and spectroscopic studies guided by herein observed results.

On the basis of these findings, we further studied the $\mathrm{eCO}_{2} \mathrm{RR}$ performance of the $\mathrm{L}-\mathrm{S}$ sample as a representative case of $\mathrm{Cu}-\mathrm{S}$ catalysts. Figure $8 \mathrm{a}$ shows the effect on the $\mathrm{FE}_{\mathrm{HCOO}}{ }^{-}$of increasing the overpotential up to $-0.9 \mathrm{~V}$ vs RHE, 


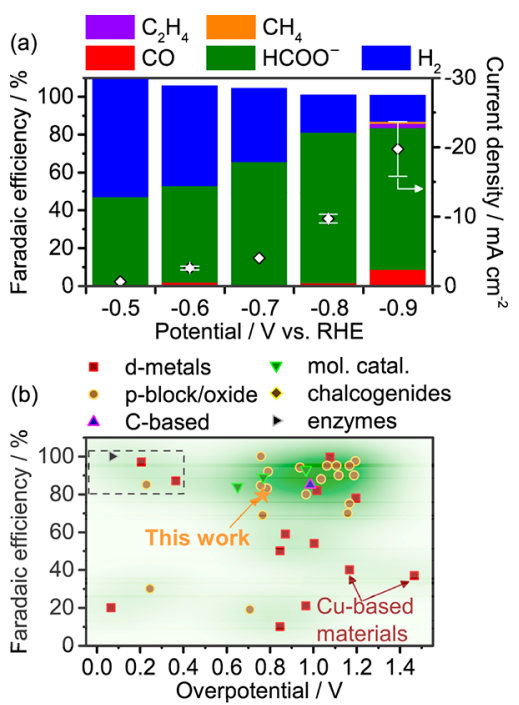

Figure 8. (a) FE and total current density as a function of applied potential over the $\mathrm{L}-\mathrm{S}$ sample. The data were obtained by $\mathrm{CA}$, performed in $0.1 \mathrm{M} \mathrm{KHCO}_{3}$ saturated with $\mathrm{CO}_{2}(\mathrm{pH} \mathrm{6.7)}$ at room temperature. (b) $\mathrm{FE}$ against overpotential compiled from literature for different families of catalytic materials for the production of formate via $\mathrm{eCO}_{2} \mathrm{RR}$. The figure is adapted with permission from reference 6 . Copyright 2017 American Chemical Society. Outstanding performances located at the left-top corner (designated with a dashed rectangle; FE $>80 \%$ and $\eta<0.40 \mathrm{~V}$ ) were reported for nonscalable and/or cost-ineffective systems (see text).

at which the selectivity to formate drops due to the appearance of other $\mathrm{eCO}_{2} \mathrm{RR}$ products. XPS analysis of the post reaction samples (SI Figure S11) disclosed the decrease in the relative intensity of the sulfide phase at more cathodic potentials, coinciding with the observed decrease of the FE toward formate. For the sake of comparison, the herein reported performance over $\mathrm{Cu}-\mathrm{S}$ is plotted alongside other electrocatalysts that favor the production of formate (Figure $8 \mathrm{~b}$ ). For the production of formate, typical overpotentials $(\eta)$ of at least $0.8 \mathrm{~V}$ are required to reach a $\mathrm{FE}$ higher than $80 \%$ using catalysts based on p-block elements, whereas the distinctive performance of $\mathrm{Cu}$-based materials is centered at around $40 \%$ FE at $\eta>1.1 \mathrm{~V}$. We note that outstanding values (FE $>80 \%$ and $\eta<0.40 \mathrm{~V})$ are currently associated with cost-ineffective systems, such as atomically controlled structures, ${ }^{37}$ precious metals, ${ }^{38}$ or enzymes. ${ }^{39}$ Further efforts have attempted to bring precious metal-based catalysts closer to practical requirements, for example, by improving their mass-activity by increasing their dispersion, ${ }^{40,41}$ which is a key prerequisite ${ }^{42}$ in these systems toward their implementation for the $\mathrm{eCO}_{2} \mathrm{RR}$. In contrast, the initially optimized $\mathrm{Cu}-\mathrm{S}$ in this study achieved a Faradaic efficiency of $80 \%$ at an overpotential of $0.76 \mathrm{~V}$, which locates it at the top of earth-abundant, cost-effective, and nontoxic electrocatalysts reported to date via aqueous $\mathrm{eCO}_{2} \mathrm{RR}$. In regard to stability, we note that the $\mathrm{Cu}-\mathrm{S}$ catalyst sustained its exclusive formate production over $12 \mathrm{~h}$ of electrolysis at $-0.8 \mathrm{~V}$ vs RHE, where a slight decrease in the average $\mathrm{FE}_{\mathrm{HCOO}^{-}}$of ca. 5\% was observed (SI Figure S12a). Interestingly, the surface state did not change appreciably. The post reaction XPS analysis unveiled that the sulfide phase remained even after the long electrolysis (SI Figure S12b), indicating that the surface state comprising $\mathrm{Cu}_{2} \mathrm{~S}$ and $\mathrm{Cu}$ generated upon the initial rapid reconstruction event is stable within a range of potentials. Theoretical studies support the enhanced stability of $\mathrm{Cu}_{2} \mathrm{~S}$ on $\mathrm{Cu}$ with respect to its bulk state induced by the intergranular precipitation of $\mathrm{Cu}_{2} \mathrm{~S}$ in the $\mathrm{Cu}$ phase. ${ }^{43}$ In this respect, the absence of any SAED patterns originating from such sulfide phases after the $\mathrm{eCO}_{2} \mathrm{RR}$ test (Figure 5) suggests the presence of small quantity of $\mathrm{Cu}_{2} \mathrm{~S}$ and/or its amorphous nature, which hampers unambiguous elucidation of the active phase at this stage and calls for further investigation. All in all, this study demonstrated the selective production of formate via aqueous $\mathrm{eCO}_{2} \mathrm{RR}$ over sulfurmodified $\mathrm{Cu}$ electrocatalysts, adding an advantageous candidate to $\mathrm{Cu}$-based electrocatalysts for this reaction. ${ }^{17-22,44-47}$

\section{CONCLUSIONS}

Copper-based electrocatalysts modified with sulfur were studied for $\mathrm{CO}_{2}$ reduction in aqueous media. Size-controlled carbon-supported nanometric $\mathrm{CuS}$ catalysts were successfully synthesized by a wet chemistry approach. These catalysts selectively produced formate with only trace amounts of $\mathrm{CO}$ at moderate overpotential (e.g., $\mathrm{FE}_{\mathrm{HCOO}^{-}}>60 \%$ at $-0.8 \mathrm{~V}$ vs RHE). A rapid and drastic reconstruction toward smaller particles, provoked by the reduction of the $\mathrm{CuS}$ phases, took place on the $\mathrm{CuS}$ particles under operation conditions, thus leading to the formation of sulfur-modified $\mathrm{Cu}$ as the material accounting for the observed electrocatalytic activity. The selectivity to formate was positively correlated with increasing initial particle sizes, which, in turn, favored the survival of larger particles (e.g., > $20 \mathrm{~nm}$ ) during the in situ reconstruction. A detectable amount of sulfur remained in the $\mathrm{Cu}$ matrix upon reaction in all cases. Bearing in mind the plausible size-activity relationship, submicron-sized $\mathrm{Cu}-\mathrm{S}$ catalysts were prepared via a solvothermal route that allowed the variation of the sulfur content. With increasing sulfur content, both the bulk and surface structure of the solvothermally prepared catalysts evolved from $\mathrm{Cu}_{2} \mathrm{O}$ to $\mathrm{CuS}$. Nevertheless, the reaction rate and $\mathrm{FE}_{\mathrm{HCOO}^{-}}$were found to be mostly insensitive to the initial sulfur content above a certain trace level, which was accounted for by the fact that the catalysts attained a similar surface configuration under the cathodic reaction conditions of the $\mathrm{eCO}_{2} \mathrm{RR}$. The solvothermally prepared electrocatalysts exhibited improved FEs to formate (ca. $80 \%$ at $-0.8 \mathrm{~V}$ vs RHE) compared with the nanometric $\mathrm{CuS}$ materials, and they sustained their high selectivity over $12 \mathrm{~h}$. Overall, these findings open up new perspectives for $\mathrm{Cu}$-based materials in the $\mathrm{eCO}_{2} \mathrm{RR}$ and provide a solid understanding of the basic characteristics shaping the behavior of $\mathrm{Cu}-\mathrm{S}$ catalysts, thus offering a valuable platform for gaining further fundamental insights leading to improved kinetics toward formate. At this stage, the developed $\mathrm{Cu}-\mathrm{S}$ sits at the top of reported performance for practical, cost-effective, and earth-abundant catalysts toward the electrocatalytic production of formate via aqueous $\mathrm{eCO}_{2} \mathrm{RR}$

\section{ASSOCIATED CONTENT}

\section{S Supporting Information}

The Supporting Information is available free of charge on the ACS Publications website at DOI: 10.1021/acscatal.7b03161.

Procedure for the calculation of Faradaic efficiency of the gas and liquid products, synthesis details and characterization of copper-based catalysts, and calculated Pourbaix diagrams for copper species (PDF) 


\section{AUTHOR INFORMATION}

\section{Corresponding Author}

*Phone: +41 44633 7120. E-mail: jpr@chem.ethz.ch.

\section{ORCID $\odot$}

Gastón O. Larrazábal: 0000-0003-4218-3514

Javier Pérez-Ramírez: 0000-0002-5805-7355

\section{Notes}

The authors declare no competing financial interest.

\section{ACKNOWLEDGMENTS}

This work was sponsored by the European Union under the aleaf project (732840-A-LEAF) and by ETH Zurich (Research Grant ETH-01 14-1). Evgeniya Vorobyeva is kindly acknowledged for TEM analyses. The authors acknowledge the Scientific Center for Optical and Electron Microscopy (ScopeM) of ETH Zurich for access to its facilities.

\section{REFERENCES}

(1) Seh, Z. W.; Kibsgaard, J.; Dickens, C. F.; Chorkendorff, I.; Nørskov, J. K.; Jaramillo, T. F. Science 2017, 355, eaad4998.

(2) Montoya, J. H.; Seitz, L. C.; Chakthranont, P.; Vojvodic, A.; Jaramillo, T. F.; Nørskov, J. K. Nat. Mater. 2017, 16, 70-81.

(3) Vayens, C. G.; White, R. E.; Gamboa-Aldeco, M. E. Modern Aspects of Electrochemistry; Springer: New York, 2008; Vol. 42, pp 89189.

(4) Kortlever, R.; Shen, J.; Schouten, K. J. P.; Calle-Vallejo, F.; Koper, M. T. M. J. Phys. Chem. Lett. 2015, 6, 4073-4082.

(5) Martín, A. J.; Larrazábal, G. O.; Pérez-Ramírez, J. Green Chem. 2015, 17, 5114-5130.

(6) Larrazábal, G. O.; Martín, A. J.; Pérez-Ramírez, J. J. Phys. Chem. Lett. 2017, 8, 3933-3944. Further permissions related to the material excerpted should be directed to the ACS.

(7) Hori, Y.; Kikuchi, K.; Suzuki, S. Chem. Lett. 1985, 14, 16951698.

(8) Hori, Y.; Wakebe, H.; Tsukamoto, T.; Koga, O. Electrochim. Acta 1994, 39, 1833-1839.

(9) Peterson, A. A.; Abild-Pedersen, F.; Studt, F.; Rossmeisl, J.; Nørskov, J. K. Energy Environ. Sci. 2010, 3, 1311-1315.

(10) Peterson, A. A.; Nørskov, J. K. J. Phys. Chem. Lett. 2012, 3, 251-258.

(11) Kuhl, K. P.; Cave, E. R.; Abram, D. N.; Jaramillo, T. F. Energy Environ. Sci. 2012, 5, 7050-7059.

(12) Kuhl, K. P.; Hatsukade, T.; Cave, E. R.; Abram, D. N.; Kibsgaard, J.; Jaramillo, T. F. J. Am. Chem. Soc. 2014, 136, 1410714113.

(13) Li, C. W.; Kanan, M. W. J. Am. Chem. Soc. 2012, 134, 72317234.

(14) Verdaguer-Casadevall, A.; Li, C. W.; Johansson, T. P.; Scott, S. B.; McKeown, J. T.; Kumar, M.; Stephens, I. E. L.; Kanan, M. W.; Chorkendorff, I. J. Am. Chem. Soc. 2015, 137, 9808-9811.

(15) Mistry, H.; Varela, A. S.; Bonifacio, C. S.; Zegkinoglou, I.; Sinev, I.; Choi, Y.-W.; Kisslinger, K.; Stach, E. A.; Yang, J. C.; Strasser, P.; Cuenya, B. P. Nat. Commun. 2016, 7, 12123.

(16) Eilert, A.; Cavalca, F.; Roberts, F. S.; Osterwalder, J.; Liu, C.; Favaro, M.; Crumlin, E. J.; Ogasawara, H.; Friebel, D.; Pettersson, L. G. M.; Nilsson, A. J. Phys. Chem. Lett. 2017, 8, 285-290.

(17) Rasul, S.; Anjum, D. H.; Jedidi, A.; Minenkov, Y.; Cavallo, L.; Takanabe, K. Angew. Chem., Int. Ed. 2015, 54, 2146-2150.

(18) Jedidi, A.; Rasul, S.; Masih, D.; Cavallo, L.; Takanabe, K. J. Mater. Chem. A 2015, 3, 19085-19092.

(19) Sarfraz, S.; Garcia-Esparza, A. T.; Jedidi, A.; Cavallo, L.; Takanabe, K. ACS Catal. 2016, 6, 2842-2851.

(20) Larrazábal, G. O.; Martín, A. J.; Mitchell, S.; Hauert, R.; PérezRamírez, J. ACS Catal. 2016, 6, 6265-6574.

(21) Larrazábal, G. O.; Martín, A. J.; Krumeich, F.; Hauert, R.; Pérez-Ramírez, J. ChemSusChem 2017, 10, 1255-1265.
(22) Shin, H.; Ha, Y.; Kim, H. J. Phys. Chem. Lett. 2016, 7, 41244129.

(23) Hietala, J.; Vuori, A.; Johnsson, P.; Pollari, I.; Reutemann, W.; Kieczka, H. Formic Acid. Ullmann's Encyclopedia of Industrial Chemistry; John Wiley \& Sons, Inc: Hoboken, NJ, 2016; pp 1-22.

(24) Gibson, H. W. Chem. Rev. 1969, 69, 673-692.

(25) Rice, C.; Ha, S.; Masel, R. I.; Waszczuk, P.; Wieckowski, A.; Barnard, T. J. Power Sources 2002, 111, 83-89.

(26) Yu, X.; Pickup, P. G. J. Power Sources 2008, 182, 124-132.

(27) Yan, B.; Concannon, N. M.; Milshtein, J. D.; Brushett, F. R.; Surendranath, Y. Angew. Chem., Int. Ed. 2017, 56, 7496-7499.

(28) Sternberg, A.; Jens, C. M.; Bardow, A. Green Chem. 2017, 19, 2244-2259.

(29) Wu, C.; Yu, S.-H.; Antonietti, M. Chem. Mater. 2006, 18, $3599-3601$.

(30) NIST X-ray Photoelectron Spectroscopy Database. X-ray Photoelectron Spectroscopy Database 20, Version 4.1; National Institute of Standards and Technology: Gaithersburg, 2012; See the following: http://srdata.nist.gov/xps/ (Accessed December 21, 2017).

(31) Kundu, M.; Hasegawa, T.; Terabe, K.; Yamamoto, K.; Aono, M. Sci. Technol. Adv. Mater. 2008, 9, 035011.

(32) Haynes, W. M.; Lide, D. R. Handbook of Chemistry and Physics, 92nd ed., CRC Press: Boca Raton, FL, 2011; pp 5-11, 5-41, 5-66, 567.

(33) Hori, Y.; Murata, A.; Takahashi, R.; Suzuki, S. J. Am. Chem. Soc. 1987, 109, 5022-5023.

(34) Cook, R. L.; MacDuff, R. C.; Sammells, A. F. J. Electrochem. Soc. 1989, 136, 1982-1984.

(35) Hori, Y.; Murata, A.; Takahashi, R. J. Chem. Soc., Faraday Trans. 1 1989, 85, 2309-2326.

(36) Feaster, J. T.; Shi, C.; Cave, E. R.; Hatsukade, T.; Abram, D. N.; Kuhl, K. P.; Hahn, C.; Nørskov, J. K.; Jaramillo, T. F. ACS Catal. 2017, 7, 4822-4827.

(37) Gao, S.; Lin, Y.; Jiao, X.; Sun, Y.; Luo, Q.; Zhang, W.; Li, D.; Yang, J.; Xie, Y. Nature 2016, 529, 68-71.

(38) Kortlever, R.; Peters, I.; Koper, S.; Koper, M. T. M. ACS Catal. 2015, 5, 3916-3923.

(39) Reda, T.; Plugge, C. M.; Abram, N. J.; Hirst, J. Proc. Natl. Acad. Sci. U. S. A. 2008, 105, 10654-10658.

(40) Min, X.; Kanan, M. W. J. Am. Chem. Soc. 2015, 137, 47014708.

(41) Rahaman, M.; Dutta, A.; Broekmann, P. ChemSusChem 2017, 10, $1733-1741$.

(42) Verma, S.; Kim, B.; Jhong, H.-R.; Ma, S.; Kenis, P. J. A. ChemSusChem 2016, 9, 1972-1979.

(43) Korzhavyi, P. A.; Abrikosov, I. A.; Johansson, B. Acta Mater. 1999, 47, 1417-1424.

(44) Hoffman, Z. B.; Gray, T. S.; Moraveck, K. B.; Gunnoe, T. B.; Zangari, G. ACS Catal. 2017, 7, 5381-5390.

(45) Li, Q.; Fu, J.; Zhu, W.; Chen, Z.; Shen, B.; Wu, L.; Xi, Z.; Wang, T.; Lu, G.; Zhu, J.-J.; Sun, S. J. Am. Chem. Soc. 2017, 139, 4290-4293.

(46) Huang, Y.; Deng, Y.; Handoko, A.; Goh, G. K. L.; Yeo, B. S. ChemSusChem, 2017, DOI: 10.1002/cssc.201701314.

(47) Lv, W.; Zhou, J.; Bei, J.; Zhang, R.; Wang, L.; Xu, Q.; Wang, W. Appl. Surf. Sci. 2017, 393, 191-196. 